\title{
PLC Based Fault Identification in Conveyors
}

\author{
Dinesh Kumar. V, Manimekalai. V, Saravanakumar. S
}

\begin{abstract}
In today's world, the assembly rate has accrued staggeringly. Commonly, engineering industries keep producing same models with slight distinction tall, colour, weight and form. And here fault identification plays a major half. In such circumstances industries can't vacant golem errors. Therefore it's necessary to develop mechanism for characteristic faults in these product in actual manner. Industrial automation primarily focuses on developing automations having low value, low maintenance, long sturdiness and to create systems user friendly as potential. Finally, here we tend to have developed a system for sorting the light-weight weight objects on the basis of height variation mistreatment proximity sensors that is controlled by Programmable Logic Controller (PLC) and the conveyor within the system passes the object in front of sensors and therefore fault identification is completed.
\end{abstract}

Index Terms: Automation, Programmable Logic Controller, Low value Automation, producing, Fault identification.

\section{INTRODUCTION}

The development of producing industries depends upon analysis in producing method and innovation in new product. The countries that have higher producing rate are better-known to be developed whereas those with very little producing are thought of underdeveloped.

During process, the staple gets remodeled into product. Once this product gets processed it earns a price available. Therefore, producing is 'adding value' to the fabric. The worth that's attained by the merchandise ought to have additional value permitting the organization to create cash out of it [1].

Generally, producing industries keep producing same models could have some product with faults and therefore fault identification plays a crucial role here. In previous days it absolutely was potential to implement toil for characteristic faults. However these days because of accrued production and for minimizing the labor expenditure for such unskilled task, industries can't afford human errors for characteristic faulty product.

As economy has continuously been a substantial consider developing business, therefore it become necessary to develop Low value Automation (LCA) for fault identification of those product in correct manner. In

Revised Manuscript Received on July 22, 2019

Dr. Dinesh Kumar. V, Kumaraguru College of Technology, Coimbatore, Tamil Nadu, India.

Ms. Manimekalai. V, Kumaraguru College of Technology, Coimbatore, Tamil Nadu, India.

Mr. Saravanakumar. S, Kumaraguru College of Technology, Coimbatore, Tamil Nadu, India. automation business, continuous innovation, finding effective ways that to reinforce productivity and cut-cost out of operations is that the key to success. Industrial automation primarily focuses on developing automations having low value, low maintenance, long sturdiness and to create systems user friendly as potential.

During this project, we've developed an occasional value Automation System for characteristic faults within the light-weight weight objects on the idea of height variation. The project primarily focuses on fault identification in objects mistreatment proximity sensors and DC intermeshed motors interfaced with Programmable Logic Controller (PLC). The gas piston is employed for pushing the thing from conveyor to individual chute conveyor. The system consists of conveyor belt that takes the objects like bottles, little boxes or packages in front of sensors and therefore fault identification is determined by PLC. PLC is programmed with 2 totally different logics, one for the great product and also the different for the faulty product. The system consists of total two proximity optical sensors or photo-electric sensors, used to notice the presence of object and height of boxes severally. The perform of main conveyer is to require the boxes ahead of height measure station. Our complete focus is on planning main conveyor. Main conveyor is high-powered by three section $\mathrm{AC}$ induction motor controlled by gear box interfaced with PLC. 3 metal plates are used for holding proximity sensors [2].

The 1st holding plate holds the beginning device whose perform is to begin the conveyor for predefined time, providing the thing is gift. This may save the energy by turning off the conveyor motor if the thing isn't gift. The close mounted $2 \mathrm{~d}$ holding plate holds two sensors that are organized to live object's height, this $2 \mathrm{~d}$ holding plate's complete assembly is thought as Height measure station. This plate includes a wring that we will modify the peak of sensors as per our demand.

The sensing element signals the conveyor to hamper then the PLC sends the signal to the mechanism that is that the gas piston to push the article out of the conveyor. Thus, the great merchandise square measure collected in separate box and faulty merchandise square measure collected in separate box.

Belt conveyor automation can powerfully enhance the

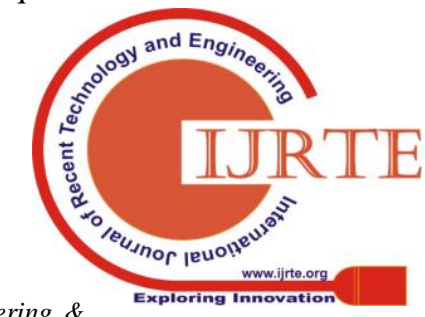

Published By: 
protection, fault identification, and management characteristics of conveyor in real time while not requiring physical man power. Thanks to advent of wireless communication technologies and high speed powerful processors, automation are going to be done to satisfy flexibility, dependableness and potency of belt conveyor.

Generally, delta series PLC could be a ladder logic primarily based system for increased performance, reduced power consumption and additional economical coincident process of multiple tasks. Wireless sensing element network consists of spatially distributed autonomous sensors to hand and glove monitor physical or environmental conditions like temperature, smoke, level, pressure etc.,

\section{LITERATURE SURVEY}

Industrial automation and artificial intelligence play vital role in growth of business. The main criteria in business square measure quality and suppleness of the merchandise. In 80 's golem were used to perform tasks like machine tending, material transfer, painting, fastening that will not need high accuracy [3].

Considering bigger role of robots it absolutely was foretold in 90's that industrial robots can become progressively important in applications that need high exactness and accuracy. Autonomous robots with sensors square measure used for accuracy and exactness in product that step by step improves the expansion of business. To attain this exactness, robots square measure programmed for one task taking sensory info.

Real time and extremely correct characteristics of little objects during a quick flowing stream would open new directions for industrial sorting processes. Recent advances in physical science and computer circuit board technology open new views for industrial application during this field.

\subsection{Existing System:}

In presently existing systems, use of various technology is formed according to budget and scope of business. It includes artificial intelligence systems, microcontroller primarily based system, sensing element \{based based mostly|primarily primarily based $\}$ system and gas based system, etc.

\section{Robotics Systems}

The robotic arm is management led mistreatment servo motors whose degree of rotation is controlled by the on timer of the heart beat rail showing at its control inputs. In line with the structure of robotic arm varied degree of rotation for the servomotor square measure assigned to hold out the operations. The arm of golem is accomplished mistreatment metallic element brackets. Four kinds of brackets square measure organized for this purpose [3]. The robotic arms square measure too expensive and advanced due to the quality and also the fabrication method.

Two kinds of the brackets square measure for holding the servo motors and 2 sorts for the extensions and interconnections of the robotic arm. The IR sensing element identifies the box and it sends the information to a microcontroller that controls the arm motion according to the peak of box. The motion of the servo motor is controlled during a manner so every box is born into a various boxes place during a preset position. The time taken by the robotic arm for one motion is about to around 0.5 seconds. Eight steps of motion of robotic arm square measure needed for a box to be picked up and to be born within the correct basket. That has motion of arm from the default position, choosing a box, motion to the correct basket, dropping the box to the basket and come back to the default position. The variety of steps taken by the arm to choose the box and drop the box counts to seven steps and from there to back to default position required one step.

Approximately time required for the microcontroller to spot height of the box is around one second. So the total time required for choosing and dropping the box as well as distinguishing the height is around 5 seconds. Four motors square measure employed in the robotic arm. One to management the move motion of the bottom, one to manage the angle at the elbow, one to manage the gliding joint movement and last one to manage the gripper, that's to carry and drop the ball. The initial position of the golemic arm once power is applied and the robot is prepared for operation. A lever mechanism is employed for gap and shutting the gripper.

So one motor is enough for the gripper management. Fingers come back nearer to choose and hold the box and move apart once it drops the box. 2 positions square measure designed for the fingers by employing a single servo motor, one in closed position and also the alternative in open position. 2 motions square measure permissible for the motor at gliding joint and elbow that is to move up and down.

\section{Sensor Based System}

The advance system of carton sorting is according to weight, recent system was supported sensing element. There have been some systems that counts that what number objects square measure going from the conveyor. Such systems create use of sensing element. Once carton passes through conveyer, at the aspect of conveyer unremarkably transmitter and receiver infrared

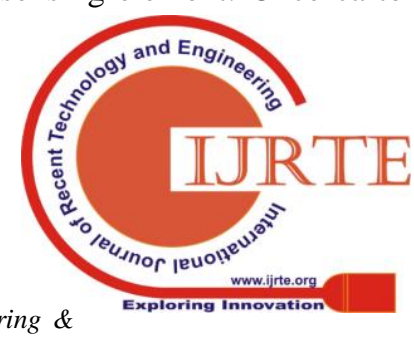

Blue Eyes Intelligence Engineering \& Sciences Publication 
sensing element were used. Once the carton cuts the infrared beam the electronic counter system in digital kind gets ' 0 ' that was counted as count. Sensing element primarily based system sense returning object and count it. However the disadvantage of the system is that it will solely senses the article it cannot calculate the burden of object. Thus it's not having the supply of sorting carton as per needed weight.

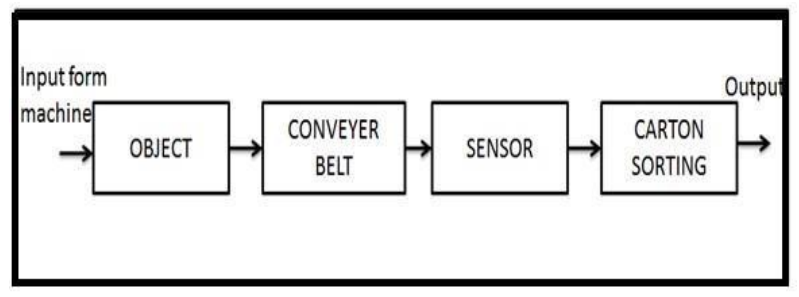

Fig 2.1 Sensor Based System

Sensor-Based Sorting is addressing new developments and applications in the field of automatic device separation techniques for primary and secondary raw materials.

\section{Microcontroller Based System}

The microcontroller primarily based systems are having kind of artificial potency as microcontroller is programmed as per the system demand. The microcontroller is programmed to count the carton

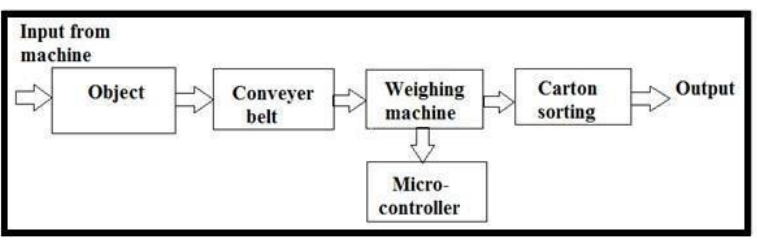

Fig 2.2 Microcontroller Based System

passing from conveyer and conjointly to live weight of carton box. As this system has its disadvantage on microcontroller measurement weight with advance measurement weight demands. There are several such systems are accessible that use on-line check-weightier to calculate the load of object. If we have a tendency to use microcontroller then value of the system get multiplied. The foremost disadvantage of mistreatment microcontroller is that its hardware needs can conjointly go on increasing as it will not contain integral timer, counter [4]. All this disadvantage of existing system is overcome in PLC primarily based object sorting automation which type object in line with the peak.

\section{Pneumatic Powered System}

A belt conveyor is employed to feed the boxes. It's driven by means that of a motor. Electrical phenomenon sensors are fastened at needed heights to kind the several boxes. 3 double acting cylinders are wont to kind the boxes once motivated by the sensors. A $5 / 2$ magnet operated spring come back direction management valve and $5 / 2$ magnet

operated direction management valves are used. The setup consists of a belt conveyor moving at an optimum speed.

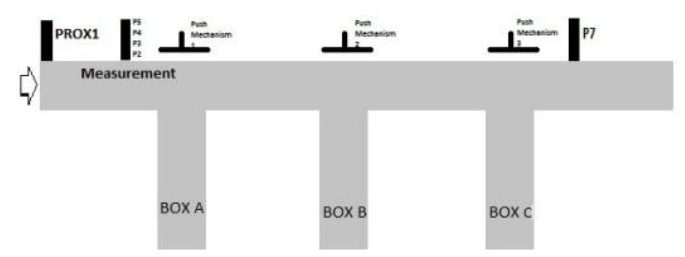

Fig 2.3 Model of Pneumatic Based System

This belt conveyor is loaded with boxes of 3 totally different heights. There are 3 totally different sensors at appropriate heights to sense the boxes. The very best length box are perceived by the three sensors. The smaller of the 2 boxes are perceived by solely initial device and can be sorted at third station.

It is terribly typical and ancient methodology to create use of gas pressure pump for pushing or sorting the objects [4]. However the major disadvantage in mistreatment all these recent ways is the setup value and their maintenance. Mistreatment gas pressure pump needs a serious setup which has compressor, management valves, air filter, pressure regulator, lubricator, direction management valve, flow management valves and every one linking assembly (pipes and joints).

\section{SYSTEM MODELLING}

The main conveyer belt can take the boxes ahead of height measure station. The most conveyor style is necessary key issue here. Main conveyor is energized by three part AC induction motor interfaced with PLC.

The system assembly include 2 holding plates, first one holds begin detector that can begin the conveyor and ordinal holding plate holds two sensors that square measure organized to live object's height, the ordinal holding plate complete assembly is thought as Height measure Station. This plate incorporates a make time for that we will modify the peak of sensors as per our demand.

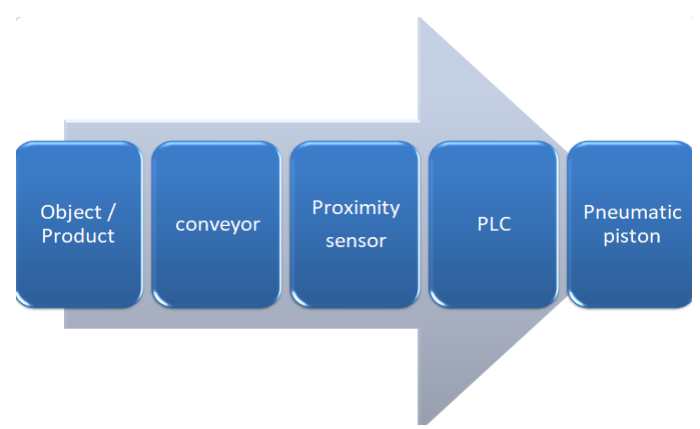

Fig 3.1 Process Block Diagram 
The push assembly consists of gas piston energized by manipulated power provide. The offset shaft of gas piston one is extended with metal plate once the great product is perceived by the detector. The piston helps to push the article onto rail. The offset shaft of gas piston two is extended with metal plate once the faulty product is perceived by the detector. The piston helps to push the article onto rail. Once the begin detector can sense the object it can signal PLC to begin main conveyor for specific period of time. Basically, guider strips square measure accustomed align objects within the center of conveyer belt, so objects won't stuck at the other a part of the system.

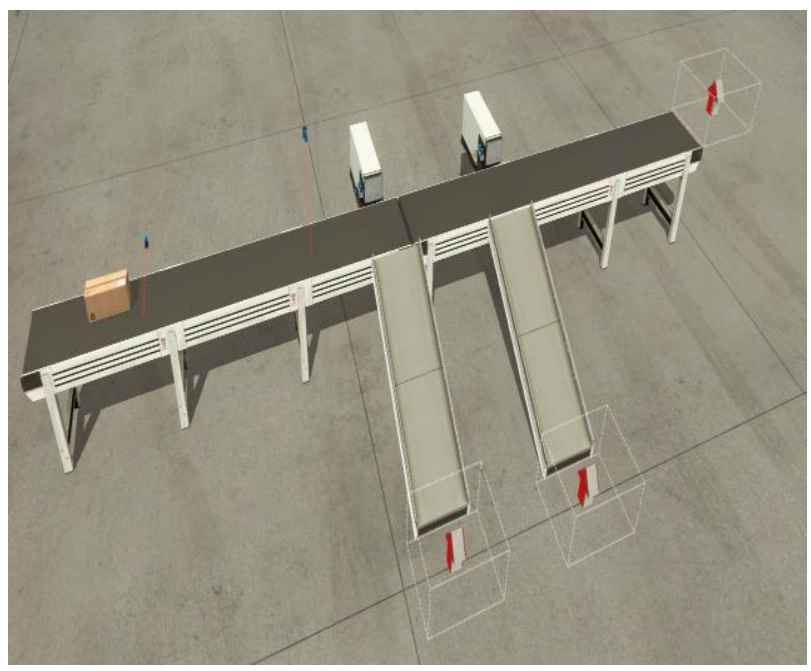

Fig 3.2 Model of the Project

Then, it's to pass from front of Height measure station. Currently the logic programmed in PLC is specified, if the article is detected by the begin detector, it'll simply begin the conveyor for fastened time. Currently the article comes ahead of the measure station. If the article is nice, the piston one is motivated and it's pushed into the rail and so the article is collected within the bin one.

If the article is faulty, the piston two is motivated and it's pushed into the rail and so the article is collected within the bin two. Thus, the fault identification is completed with the assistance of sensors and pistons controlled by PLC.

\subsection{Description of Flow Chart:}

1. The objects square measure fed to main \{the begin the beginning\} detector can start the conveyor for the predefined time.

2. Whereas passing from the guider strips, the objects can reach ahead of height measure station, wherever its height can be measured by victimisation photo-electric sensors arrangement.

3. If the article is nice, the conveyor can holdup and actuates piston one to kind smart object into bin one.

4. If the article is faulty, the conveyor can holdup and actuates piston two to kind faulty object into bin two.

5. The conveyor stops running, if no different objects is detected on the conveyor that is controlled by PLC.

\subsection{Components of the System}

- Photo-electric sensor: A photoelectrical sensor, or photograph eye, is associate instrumentation accustomed discover the space, absence, or presence of associate object by employing a lightweight transmitter, typically infrared, and a photoelectrical receiver. They're for the most part utilized in industrial producing.

The system consists of total four proximity optical sensors or photo-electric sensors, used to notice the presence of object and height of boxes. IRD 183 diffuse sort photograph electrical detector is employed in our project.

A sensing element is associate musical instrument that detects the presence of metal near. Metal detectors square measure helpful for locating metal inclusions hidden at intervals objects. Proximity sensors square measure usually created with four main elements:

- a coil and primary solid solution core assembly

- an generator

- a convertor/trigger circuit (detector)

- output device

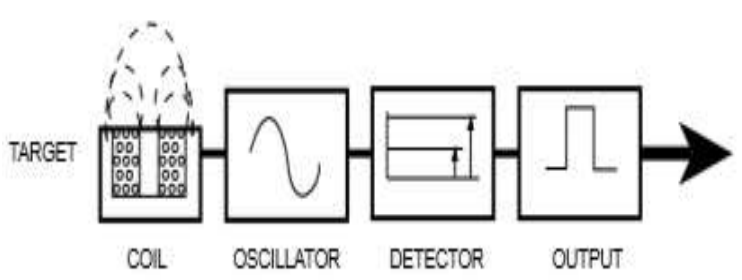

Fig 3.3 Proximity Sensor Elements

- Phase AC induction motor: To energies assembly of conveyer belt 3 part induction motor is employed. These motor is employed in convention with VFD that is ready to manage the speed consistent with demand 
- Conveyor belt: Conveyors square measure sturdy and reliable parts utilized in automatic distribution and reposition. Together with pc controlled pallet handling instrumentation this permits for additional economical retail wholesale and producing distribution.

It is thought-about a labor saving system that permits giant volumes to move rapidly through a method, permitting firms to ship or receive higher volumes with smaller space for storing and with less labor expense.

These square measure the India rubber belts that advance auriferous rollers referred to as idlers and square measure used for shifting of coal from one place to different places. Coal helps fuel stoves and different devices round the world. Once it's extracted from beneath the bottom, there square measure numerous choices on the market once it involves transporting it to wherever it has to go. When it's fell upon the process facility or different commercial/industrial space, it is time to unload it onto a conveyer belt.

You'll either shovel it out on your own or dump it out of the vehicle it had been transported in before it reaches its next destination. Conveyor belts are accustomed transport material into process instrumentation and back out once more. These belts optimize productivity.

Pneumatic Piston: Pneumatic pistons square measure mechanical devices that use the ability of propellant to supply a force in a very reciprocatory linear motion.

Like hydraulic cylinders, one thing forces a piston to maneuver within the desired direction. The piston may be a disc or cylinder, and also the connecting rod transfers the force it develops to the article to be touched. Engineers typically favour to use mechanics as a result of their quieter, cleaner, and don't need giant amounts of area for fluid storage.

In a gas system, energy is hold on in a very potential state underneath the shape of compressed gas. Operating energy (kinetic energy and pressure) ends up in a gas system once the compressed gas is allowed to expand. To perform any applicable quantity of labour then, a tool is required which may provide associate air tank with a spare quantity of air at a desired pressure. There square measure many various cylinder sorts. The cylinders utilized in our paper square measure listed below:

- Single acting spring come back cylinder

- Double acting cylinder

- Directional management Valves

- FOUR method Valve

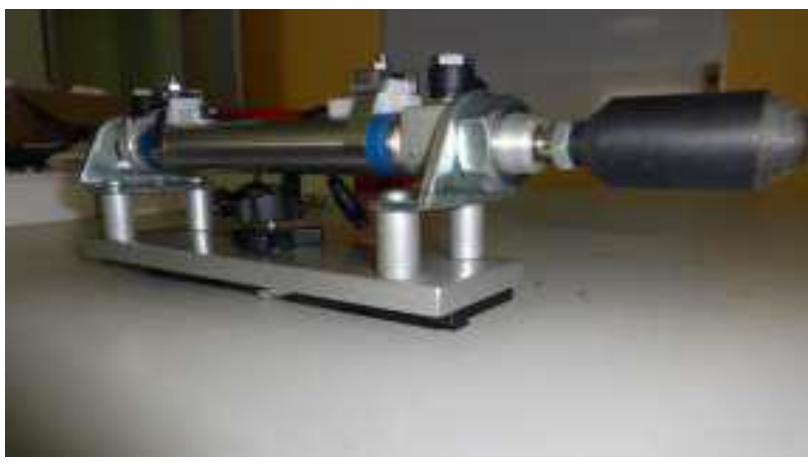

Fig 3.4 Pneumatic Piston

- Programmable Logic Controller: A programmable logic controller (PLC) is basically a user friendly micro-processor primarily based PC, consisting of hardware and package, designed to management the operation of Industrial instrumentation and processes. A crucial advantage of the PLC is that it may be simply programmed and reprogrammed.

Programmable logic controller (PLC) may be a system victimisation electronic operations. It's simple storing procedures, handy extending principles, functions of sequential/position management, regular count and input/output management square measure wide applied to the sphere of business automation management.

Some leading PLC maker's square measure FTO, Allen Bradley, Honeywell, Siemens, GE Fanuc, Mitsubishi, Modicon, Omron etc. To program PLC we have a tendency to square measure victimisation CODESYS (Controller Development System) that may be a development atmosphere for programming controller applications consistent with the international industrial customary IEC61131-3[5]. CODESYS licenses square measure free of charge and might be put in wrongfully while not copy protection on additional workstations.

We square measure on the market with the 250 totally different microcontroller and microchip from fifty semiconductor vendors in the market still we have a tendency to square measure victimisation PLC owing to following blessings.

- Small physical size

- Less maintenance

- Online programming potential

- Extension of I/O ports is feasible

- High speed of operation

- Compatible with pc communication

- LPC device

- Cost effective for dominant complicated systems 


\subsection{Methodology}

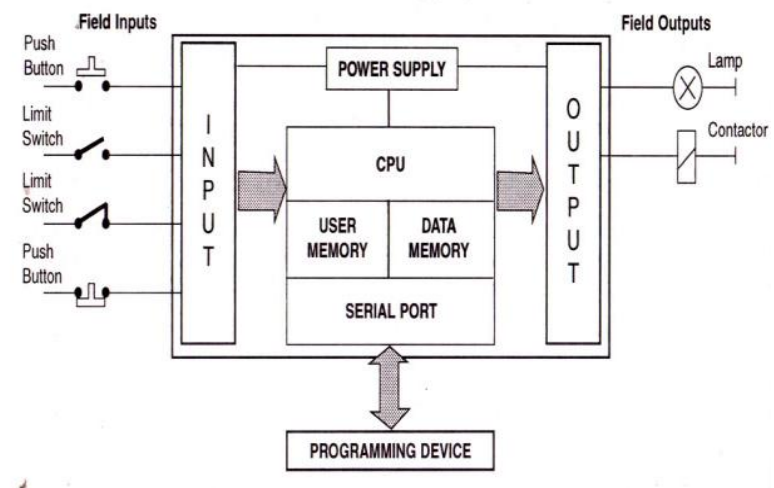

The methodology of the project is as follows

Fig 3.5 Process Methodology

\begin{tabular}{|c|c|c|c|c|c|c|c|}
\hline \multirow[t]{2}{*}{$\begin{array}{l}\text { Home } \\
\text { Sensor }\end{array}$} & \multirow[t]{2}{*}{$\begin{array}{l}\text { Position } \\
\text { sensor }\end{array}$} & \multirow[t]{2}{*}{$\begin{array}{l}\text { End } \\
\text { Sensor }\end{array}$} & \multirow[t]{2}{*}{$\begin{array}{c}\text { Camera } \\
\text { sensing }\end{array}$} & \multicolumn{2}{|c|}{$\begin{array}{c}\text { DAQ O/P } \\
\text { Voltage }\end{array}$} & \multirow{2}{*}{$\begin{array}{c}\text { Piston } \\
1 \\
\text { (Good) }\end{array}$} & \multirow{2}{*}{$\begin{array}{c}\text { Piston } \\
2 \\
\text { (Fault) }\end{array}$} \\
\hline & & & & $\begin{array}{c}\text { Analog } \\
\text { o/p } \\
\text { (a0) }\end{array}$ & $\begin{array}{c}\text { Analog } \\
\text { o/p } \\
\text { (a1) }\end{array}$ & & \\
\hline ON & - & - & - & - & - & - & - \\
\hline \multirow[t]{2}{*}{ - } & $\mathrm{O}$ & \multirow[t]{2}{*}{ - } & \multirow[t]{2}{*}{ ON } & $\mathrm{ON}$ & - & $\mathrm{ON}$ & - \\
\hline & $\mathrm{N}$ & & & - & ON & - & ON \\
\hline \multirow[t]{2}{*}{ - } & \multirow[t]{2}{*}{ - } & \multirow[t]{2}{*}{ ON } & \multirow[t]{2}{*}{ - } & ON & - & ON & - \\
\hline & & & & - & ON & - & $\mathrm{ON}$ \\
\hline
\end{tabular}

Table 3.1 Methodology

The object is placed on the conveyor. The house detector that is that the icon electrical detector senses the article and makes the motor to endure a pre- outlined amount, till it reaches the fault detection station. The fault detection station has the second physical phenomenon detector that stops the motor once it detects the article. The metal good Camera that is placed at the fault detection station captures the image of the article and measures the dimension of the article.

In this project, the size of the article are taken into activity. The check object utilized in the project is that the tiny cylinder, during which inner diameter of the article varies for every object. The target of the examination is to categorise the article with inner diameter larger than a pair of $\mathrm{cm}$ pretty much as good product and objects with inner diameter but a pair of $\mathrm{cm}$ as unhealthy product.

Inner diameter $>$ a pair of is nice PRODUCT Inner diameter $<$ a pair of is unhealthy PRODUCT

After inspecting the dimension of the article, the motor starts once more so reaches the tip detector, that is additionally a physical phenomenon detector. Once this detector senses the article, it sends signal to PLC to actuate the gas system. If the article is nice, then the piston one are going to be motivated. The tip of the piston is connected with the nice objects grouping box. Once the piston is motivated, eventually the grouping box moves forward and collects the nice object in to the box. Once the article is collected the piston is motivated backward and waits for subsequent instruction. The forward and reverse motion of the gas cylinder is enabled with the assistance of the coil valve connected with the compressor.

If the article is unhealthy, then the piston a pair of are going to be motivated. The tip of the piston is connected with the nice objects grouping box. Once the piston is motivated, eventually the grouping box moves forward and collects the unhealthy object in to the box. Once the article is collected the piston is motivated backward and waits for subsequent instruction. The forward and reverse motion of the gas cylinder is enabled with the assistance of the coil valve connected with the compressor.

This operation repeats whenever the article is perceived by the house detector. Once the detector detects no a lot of objects at an amount of twenty seconds, then the motor stops running. This can be for power saving method.

\section{PERFORMANCE ANAYLYSIS}

Performance analysis includes the performance of the device with varied inputs and by exploitation completely different topologies applying to the device. We tend to distinguish 3 basic steps within the performance analysis process: knowledge assortment, knowledge transformation, and knowledge visualisation. Knowledge assortment is that the method by that knowledge concerning program performance are obtained from Associate in nursing death penalty program. Mitsubishi one thousand Nexgenie PLC need CoDeSys computer code for writing purpose. The PLC and laptop is connected by a RS232 cable. The programming of the PLC will be perform in three completely different languages. Out of that ladder diagram is desirable because it provides simple electrical device illustration and once development of the ladder logic it may be regenerate to secured code like STL [5].

\subsection{Interfacing used in project}

In our project we tend to have created use of varied parts such as PLC, VFD, DC engaged motor, AC $3 \phi$ induction motor, sensors, etc. together with varied power provides like single section AC, 3 section $\mathrm{AC}, 5 \mathrm{~V}$ and $24 \mathrm{~V}$ DC. Every of those part needed their own regulated power \{offer correct|for correct\} functioning which may solely be achieved 
exploitation proper interfacing or just we will use readymade 230 vacation input to five VDC output with 2A.Following are the interfacing utilized in our project: -

\section{- AC mains to PLC: -}

PLC works on twenty four V DC that will be obtained from regulated power offer. The input to regulated power offer is $230 \mathrm{~V}$ AC Associate in nursing as an output it provides $24 \mathrm{~V}$ DC.

\section{- Motor to PLC: -}

A contactor is Associate in nursing electrically controlled switch used for switch Associate in nursing wattage circuit. A contactor is usually controlled by a circuit that features an abundant lower power level than the switched circuit, like a 24-volt coil magnet dominant a 230 -volt motor switch.

\section{CONCLUSION}

In this project report, we've got tried to make a setup which will decrease human effort Associate in Nursing succeeded to an extent by exploitation the low price automation system (LAC) to avoid risk, improve accuracy, increase speed of production and scale back the cycle time. Limitations are going to be there because of the sensible difficulties in programming of the project according the convenience of the materials and parts. This setup will be any improved to a sorting system that kinds the things based mostly on the different physical thought. This will be achieved exploitation the varied sensors. In business it will be used for sorting of varied objects, tools, with high degree of accuracy Associate in Nursing quality with an automation.

PLCs are necessary half to style with a lot of reliable and fewer power consumption for conveyor management operations. This proposal offers higher accuracy, reliable operation in time period wherever the human life is incredibly necessary that, it protects them from a significant risk throughout fault condition. This proposal is automatic fault detector within the conveyor.

\section{REFERENCES}

[1] Manjunatha "Postal Automation System for Mail Sorting" International Journal of Emerging Technology and Advanced Engineering (ISSN 2250-2459) Volume 5, Issue 3, March 2015)

[2] Albert T. Jones, Charles R. McLean,"A proposed hierarchica control model for automated manufacturing systems", National Bureau of Standards, Gaithersburg, Maryland, USA

[3] Y V Aruna, Beena S "Automatic convey or System with In-Process Sorting Mechanism using PLC and HMI System", Int. Journal of Engineering Research and Applications ISSN: 2248-9622, Vol. 5, Issue 11, (Part - 3) November 2015, pp.37-42
[4] Saurin Sheth, Rahul Kher, Rushabh Shah, Parth Dudhat, Pratyush Jani "Automatic Sorting System Using Machine vision", DOI: $\quad$ 10.13140/2.1.1432.1448 Conference: Multi-Disciplinary International Symposium on Control, Automation \& Robotics, At DDIT, Nadiad, Volume: 1

[5] D. A. Wahab, A. Hussain, E. Scavino, M.M. Mustafa and H. Basri "Development of a Prototype Automated Sorting System for Plastic Recycling" American Journal of Applied Sciences 3 (7): 1924-1928, 2006 ISSN 1546-9239 (C) 2006 Science Publications

\section{AUTHORS PROFILE}

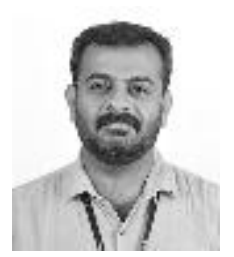

Dr. Dinesh Kumar. V completed Ph.D. in 2017 at Anna University, Chennai. His area of research is Process Control. Published 14 papers in Journals.

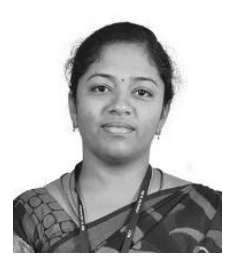

Ms. Manimekalai. V pursuing her Ph.D. at Anna University, Chennai. Her area of Research is Process Control. Published 11 papers in Journals.

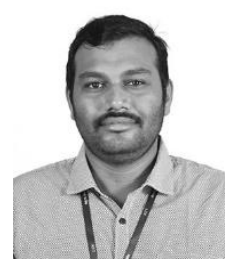

Mr. Saravanakumar. S completed his M.E. degree at Anna University, Chennai. His area of research is VLSI design. Published 6 papers in Journals. 